\title{
A structural model of technology acceptance
}

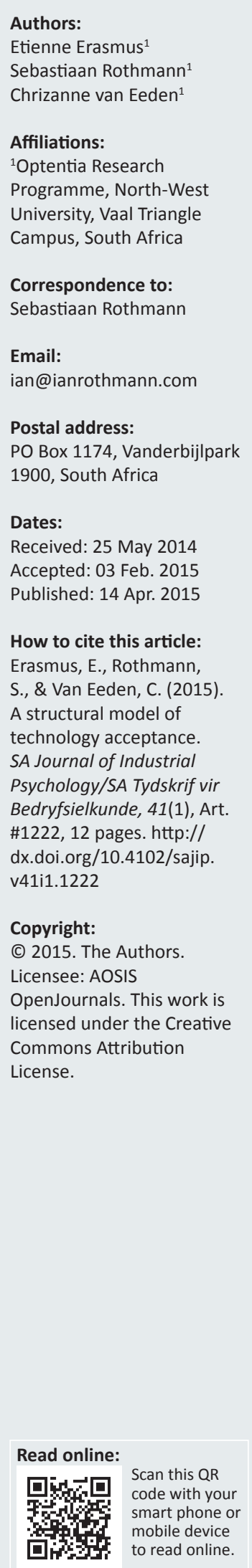

\section{Authors:}

Affiliations:

University, Vaal Triangle

Campus, South Africa

Correspondence to:

Email:

rothmann.com

PO Box 1174, Vanderbijlpark

Dates:

Received: 25 May 2014

Accepted: 03 Feb. 2015

A structural model of

technology acceptance.

SA Journal of Industrial

\#1222, 12 pages. http://

dx doi.org/10.4102/sajip.

Copyright:

Commons Attribution

License.
Programme, North-West

to read online.
Orientation: Enterprise resource systems have not always led to significant organisational enhancement and many projects in which these systems have been implemented turn out to be over budget, not on time and unsuccessful.

Research purpose: The aim of this study was to test the technology acceptance model within a South African SAP ${ }^{\circledR}$ Enterprise Resource Planning user environment.

Motivation for the study: No study could be traced in which the technology acceptance model has been evaluated in the South African context.

Research approach, design and method: A cross-sectional survey design was used. The 23item Technology Acceptance Model Questionnaire was deployed amongst SAP ${ }^{\circledR}$ Enterprise Resource Planning users $(N=241)$.

Main findings: The results confirmed significant paths from perceived usefulness of the information system to attitudes towards and behavioural intentions to use it. Furthermore, behavioural intention to use the system predicted actual use thereof. Perceived ease of use indirectly affected attitudes towards and behavioural intentions to use via perceived usefulness of the information system.

Practical/managerial implications: Practitioners should build user confidence by ensuring the ease of use of a new system, providing relevant education, training and guidance and reiterating its usefulness and future added value to the user's job and career.

Contribution/value-add: This study contributes to scientific knowledge regarding the influence of individuals' perceptions of information system usage on their attitudes, behavioural intentions and actual use of such a system.

\section{Introduction}

Business organisations are constantly looking for ways to gain an advantage over their competitors (Beyleveld \& Schurink, 2005; Castaneda \& Toulson, 2013). Historically, their focus was on producing as much as possible without considering exact demand (Turner \& Chung, 2005). Recently, businesses have embarked upon finding more efficient ways to deal with large turnovers (Umble, Haft \& Umble, 2003). One way of achieving this is by employing an Enterprise Resource Planning (ERP) system. An ERP system is a mandatory, integrated, customised, packaged software-based system that handles most of the system requirements in all business operational functions such as finance, human resources, manufacturing, sales and marketing (Wua, Onga \& Hsub, 2008). Although expectations from ERP systems are high, these systems have not always led to significant organisational enhancement (Soh, Kien \& Tay-Yap, 2000) and most ERP projects turn out to be over budget, not on time and unsuccessful (Abugabah \& Sanzogni, 2010; Hong \& Kim, 2002; Kumar, Maheshwari \& Kumar, 2003).

Previous studies indicate that ERP project failures result because of poor project communication (Somers \& Nelson, 2004), lack of senior management support (Al-Mashari, Al-Mudimigh \& Zairi, 2003), presence of ethnic differences (Yusuf, Gunasekaran \& Abthorpe, 2004), low user acceptance (Amoako-Gyampah \& Salam, 2004; Shih \& Huang, 2009), ineffective integration of systems (Al-Mashari et al., 2003), user dissatisfaction (Beyleveld \& Schurink, 2005; Yu, Li \& Gagnonc, 2009) and inadequate system training (Amoako-Gyampah \& Salam, 2004). The continued increase in ERP system failures led researchers to seek solutions (Gumussoy, Calisir \& Bayram, 2007), resulting in a growing body of research examining the predictors of information technology acceptance and utilisation amongst ERP users (Chau \& Hu, 2002; Esteves-Sousa \& Pastor-Collado, 2000; Liang, Saraf, Hu \& Xue, 2007; Nah \& Lau, 2001; Venkatesh, Morris, Davis \& Davis, 2003). Adam, Kotzé and Van der Merwe (2011) report that the most important factors within a South African ERP environment are (1) a satisfying user experience, (2) simplicity and 
ease of use, (3) fast system response, (4) meeting user work output expectation and (5) self-learning.

The interaction between human factors and technological design factors such as system complexity, ergonomic layout and interface responsiveness, both during the preimplementation and post-implementation phases of ERP systems, are regarded as important focus areas of research and practice for industrial and organisational (I/O) psychologists (Schultz \& Schultz, 2014). More specifically, however, Cable and O'Driscoll (2010) found that 39\% of I/O psychologists in their research engaged in activities related to human factors and technology, although they only spent between $1 \%$ to $9 \%$ of their time on these activities. Although this may be attributed to limited work opportunities, a more thorough analysis revealed that it is more likely that the work activities of $\mathrm{I} / \mathrm{O}$ psychology practitioners are seen as more philosophical about the application of the principles of the behavioural sciences, embracing the humanistic model of organisational functioning. They conclude that I/O psychology practitioners could differentiate themselves from other practitioners 'by extending their scope of practice into what may be perceived as opportunities for the further application of the behavioural sciences' (Cable \& O'Driscoll, 2010, p. 18). Furthermore, this scope extension should be aimed at full exploitation of the capabilities of complex technologies such as ERP, by deliberately promoting technology acceptance amongst system users (Youngberg, Olsen \& Hauser, 2009).

Information technology (IT) acceptance research has yielded many competing models for explaining the relation between user attitudes, perceptions and beliefs and eventual system use (Meade \& Islam, 2006; Venkatesh et al., 2003). The most commonly used models include the diffusion of innovations (Rogers, 1995), the theory of reasoned action (Ajzen \& Fishbein, 1975), the theory of planned behaviour (Ajzen \& Madden, 1986) and the technology acceptance model (Davis, 1986).

From these models, the technology acceptance model, an adaptation of the theory of reasoned action (Koh, Prybutok, Ryan \& Wu, 2010), proved to be the most extensively used by information system researchers in their attempts to determine the predictors of system usage behaviour, perhaps because of its meticulousness (Etsebeth, 2012), parsimony and its magnitude of empirical support (Taylor \& Todd, 1995). It is a powerful, robust and commonly employed model for predicting and explaining user behaviour towards information system usage (Hong, Thong, Wong \& Tam, 2002; Legris, Ingham \& Collerette, 2003; Surendran, 2012; Tome, Johnston, Meadows \& Nyemba-Mudenda, 2014). Additionally, an increased need has developed for studies that examine and extend the technology acceptance model in complex (Wu \& Wang, 2005), mandatory (Lee et al., 2003) IT settings. Therefore, the technology acceptance model (TAM) has been extended to address specific research objectives, namely (2) TAM2, which aims at assisting in the designing workplace interventions to enhance user acceptance of new systems, (2) the unified technology acceptance model (UTAUT), which focuses on measuring the likelihood of new systems, and (3) TAM3, assisting managers and decisionmakers to make informed decisions about workplace interventions (Etsebeth, 2012).

The technology acceptance model has been successfully tested, across a wide variety of applications, by several previous studies in countries such as the United States of America, Japan, Switzerland, New Zealand, Hong Kong, Singapore, Malaysia, the Arab world and the United Kingdom. However, from available literature, there is little evidence that the technology acceptance model has been investigated in developing countries and specifically in South Africa (Averweg, 2008). Therefore, the aim of this study was to test the technology acceptance model in a South African manufacturing organisation. This study will contribute to scientific knowledge regarding relations amongst individuals' perceptions of information system usage, their attitudes, behavioural intentions and actual use of such a system within a South African context.

\section{The technology acceptance model}

The technology acceptance model consists of six distinct yet causally related constructs, namely external variables, perceived ease of use, perceived usefulness, attitude towards using, behavioural intention to use and actual system use (Davis, Bagozzi \& Warshaw, 1989; Koh et al., 2010). In the technology acceptance model, perceived ease of use and perceived usefulness determine an individual's information systems acceptance (Lee, Kozar \& Larsen, 2003; Surendran, 2012) by determining their attitude towards using and subsequent behavioural intention to use, which culminates in actual system use (Wu \& Wang, 2005). Perceived usefulness is used as both a dependent and an independent variable since it is predicted by perceived ease of use and in turn predicts attitude towards using and behavioural intention to use simultaneously (Davis et al., 1989; Koh et al., 2010; Lee et al., 2003). The perceived ease of use, attitude towards using and behavioural intention to use components represent the core functions of the technology acceptance model, whereas external variables and actual system use serve merely as input to and output from the model respectively. Figure 1 demonstrates the technology acceptance model as a theoretical framework and its internal construct associations.

The rationale of the technology acceptance model is that the influence of external variables on technology acceptance behaviour is mediated through user beliefs and attitudes, in which beliefs represent a degree of instrumentality tied to action and attitudes are purely affective. Beliefs relate to an individual's subjective assessment that performing some behaviour will result in a specific consequence, whereas attitudes relate to an individual's positive or negative affective feelings about performing the behaviour (Lee et al., 2003). 


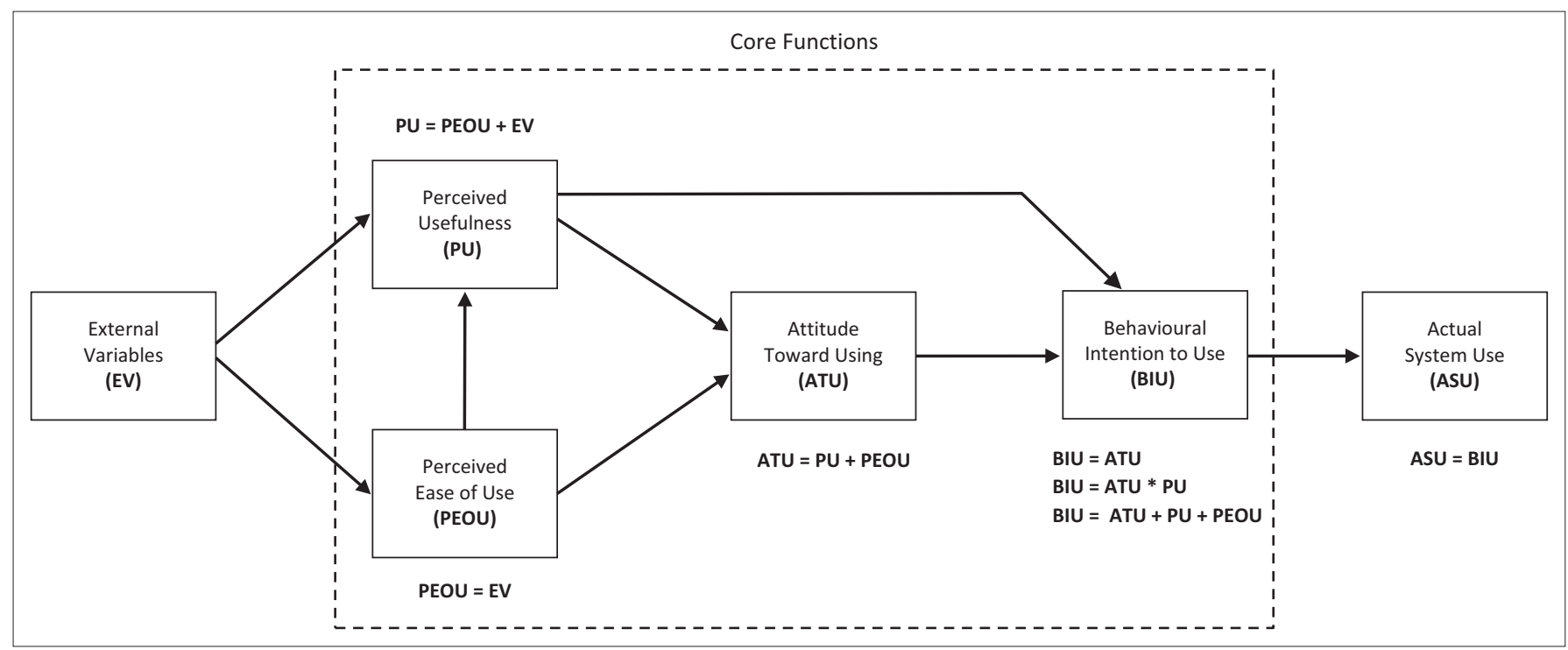

Source: Adapted from Davis et al. (1989).

FIGURE 1: Technology acceptance model.

Both perceived ease of use and perceived usefulness are belief constructs that are indirectly influenced by external variables in reinforcing a user's belief that using a particular system could improve their performance and through their belief that using a particular system (by implication, ERP) will be free of effort (Brown, 2002; Saade \& Bahli, 2005; Surendran, 2012). External variables are therefore a bridge between internal beliefs, attitudes and intentions represented in the technology acceptance model and various individual differences, situational restrictions and organisational interventions imposing on behaviour (Guritno \& Siringoringo, 2013). Identifying external variables and recognising their impact enables system developers to manipulate these variables and in so doing have better control over user attitude towards using and behavioural intention to use and the subsequent enhanced actual system use (Hong et al., 2002). Previous researchers have identified two main categories of external variables, namely individual differences (e.g. self-efficacy, innovativeness and computer attitudes) and system characteristics (e.g. voluntariness, relative advantage and complexity), as identified by Lee et al. (2003).

Davis, Bagozzi and Warshaw (as cited in Guritno \& Siringoringo, 2013) found that although perceived usefulness and perceived ease of use are distinct dimensions, an enhanced perceived ease of use contributes to better performance, thus having a direct influence on perceived usefulness.

Research has further revealed that a relation exists between perceived usefulness and attitude towards using, and between perceived ease of use and attitude towards using new technology (Legris et al., 2003; Gefen \& Straub, 2000; Gumussoy et al., 2007; Guritno \& Siringoringo, 2013; Moon \& Kim, 2001). Attitude towards using involves judgment on whether a behaviour is good or bad and whether the user is in favour of or against performing it (Leonard, Cronan \&
Kreie, 2004) and has a direct effect on the intention to use IS or ERP systems in the future (Guritno \& Siringoringo, 2013; Liao, Shao, Wang \& Chen, 1999). According to the technology acceptance model, attitude towards using is jointly determined by perceived ease of use and perceived usefulness (Guritno \& Siringoringo, 2013).

The technology acceptance model further proposes that computer usage is ensured by behavioural intention to use, which predicts a user's intention to perform an intentional act such as deciding to accept and use an information system. Behavioural intention to use has also been found to accurately predict the actual use of a computer information system (Guritno \& Siringoringo, 2013; Recker, Rosemann, Green \& Indulska, 2006; Yu et al., 2009). Behavioural intention to use is influenced by attitude towards using and perceived usefulness (Chau \& Hu, 2002; Guritno \& Siringoringo, 2013).

Historically, technology acceptance model research has been done, covering traditional and relatively simple yet important environments, such as personal computing, email systems, word processing and spreadsheet software (Hong et al., 2002). However, with the introduction and acceptance of complex information systems such as ERP that cut across functional and organisational boundaries and require business process reengineering during implementation, it was clear that there is an increased need to study and extend the technology acceptance model in complex information systems settings (King \& He, 2006). Several researchers have responded to this need and conducted research on the more complex information systems environment of ERP (see Table 1).

Apart from the study done by Seymour, Makanya and Berrangé (2007) within an academic environment using a hybrid version of the technology acceptance model, namely the UTAUT, no South African research study could be traced that used the technology acceptance model as a foundation 
TABLE 1: Examples of TAM research in the ERP environment.

\begin{tabular}{|c|c|}
\hline Researchers & Results \\
\hline Amoako-Gyampah and Salam (2004) & $\begin{array}{l}\text { Managerial interventions, such as training and communication influences the acceptance of Enterprise Resource Planning (ERP) } \\
\text { technology. }\end{array}$ \\
\hline Gumussoy, Calisir and Bayram (2007) & $\begin{array}{l}\text { Subjective norms, perceived usefulness and education level are determinants for behavioural intention to use the Enterprise } \\
\text { Resource Planning (ERP) system. }\end{array}$ \\
\hline Legris, Ingham and Collerette (2003) & $\begin{array}{l}\text { The Technology Acceptance Model (TAM) explains only about } 40 \% \text { of Enterprise Resource Planning (ERP) system use due to } \\
\text { significant factors not included such as human and social change processes and adoption of the innovation model variables. }\end{array}$ \\
\hline Seymour, Makanya and Berrangé (2007) & $\begin{array}{l}\text { Factors such as performance expectancy, effort expectancy, project communication, training and shared beliefs were all found to } \\
\text { be antecedents to symbolic adoption and age was found to have a moderating influence on the relationships between symbolic } \\
\text { adoption and: } \\
\text { - Effort expectancy } \\
\text { - Training } \\
\text { - Shared belief } \\
\text { - Project communication }\end{array}$ \\
\hline Shih and Huang (2009) & $\begin{array}{l}\text { Structural equation modelling demonstrated that top management support strongly and positively affects computer self-efficacy } \\
\text { (CSE), perceived usefulness (PU) and perceived ease of use (PEOU). } \\
\text { CSE had an insignificant effect on PU, but was found to directly influence PEOU. } \\
\text { PU influenced behavioural intention, but did not significantly affect actual system usage (ASU). } \\
\text { PEOU was found to directly affect behavioural intention to use (BIU). } \\
\text { Finally, BIU positively and directly affects ASU. }\end{array}$ \\
\hline
\end{tabular}

to examine the mediating influence of shared beliefs in the benefits of the ERP system leading towards end user acceptance and usage within a corporate environment.

\section{Purpose and hypotheses}

The purpose of this study was to determine, within a South African corporate ERP environment, the internal relations between technology acceptance model constructs and their mediating influence towards actual system use. Based on this objective, eight hypotheses were proposed as depicted in Figure 2.

Perceived ease of use is defined as the extent to which a person believes that using a particular system will be free of effort whereas perceived usefulness is defined as the extent to which a person believes that using a particular system will enhance their job performance (Davis, 1989). Previous research by Amoako-Gyampah and Salam (2004) as well as Davis (1989) shows that perceived ease of use is positively related to perceived usefulness. For this study, we hypothesise that if users consider an ERP system as being easy to use they will also find it more useful.

\section{Hypothesis 1}

Perceived ease of use relates positively to perceived usefulness during the user acceptance process of an ERP system.

Attitude towards using involves decisions on whether a behaviour is good or bad and whether the user is in favour of or against performing it (Leonard et al., 2004). Malhotra and Galletta $(1999,2005)$ report that perceived ease of use and perceived usefulness both have a positive effect on a system user's attitude to use the system. Based on their findings, we postulate that should an ERP user view the use of such a system to be effortless and useful, they will demonstrate a positive attitude towards using the system.

\section{Hypothesis 2}

Perceived usefulness relates positively to attitude towards using during the user acceptance process of an ERP system.

\section{Hypothesis 3}

Perceived ease of use relates positively to attitude towards using during the user acceptance process of an ERP system.

Davis et al. (1989) found that perceived usefulness not only has an influence on attitude towards using, but also has a direct positive effect on behavioural intention to use. This study therefore suggests that should a user deem the ERP system useful, they will instinctively have an intention to use it.

\section{Hypothesis 4}

Perceived usefulness relates positively to behavioural intention to use during the user acceptance process of an ERP system.

Behavioural intention is defined as a user's personal probability to use the system in question. The effect of attitude towards using on behavioural intention to use has been reported by Amoako-Gyampah and Salam (2004), Chau and $\mathrm{Hu}$ (2002) and Venkatesh et al. (2003) as being positive. Hence, this study hypothesises that, should a system user have a positive attitude towards using an ERP system, such a user would also have an intention to use the system.

\section{Hypothesis 5}

Attitude towards using relates positively to behavioural intention to use during the user acceptance process of an ERP system.

Actual use is a measure of the frequency of system use ('how often') and the volume of system use ('how much') by the user (Malhotra \& Galletta, 1999). Behavioural intention to use has also been found to accurately predict the actual use of a computer information system (Guritno \& Siringoringo, 2013; Recker et al., 2006; Yu et al., 2009). We therefore postulate that frequency and volume of ERP use is directly influenced by a user's behavioural intention to use such a system. 


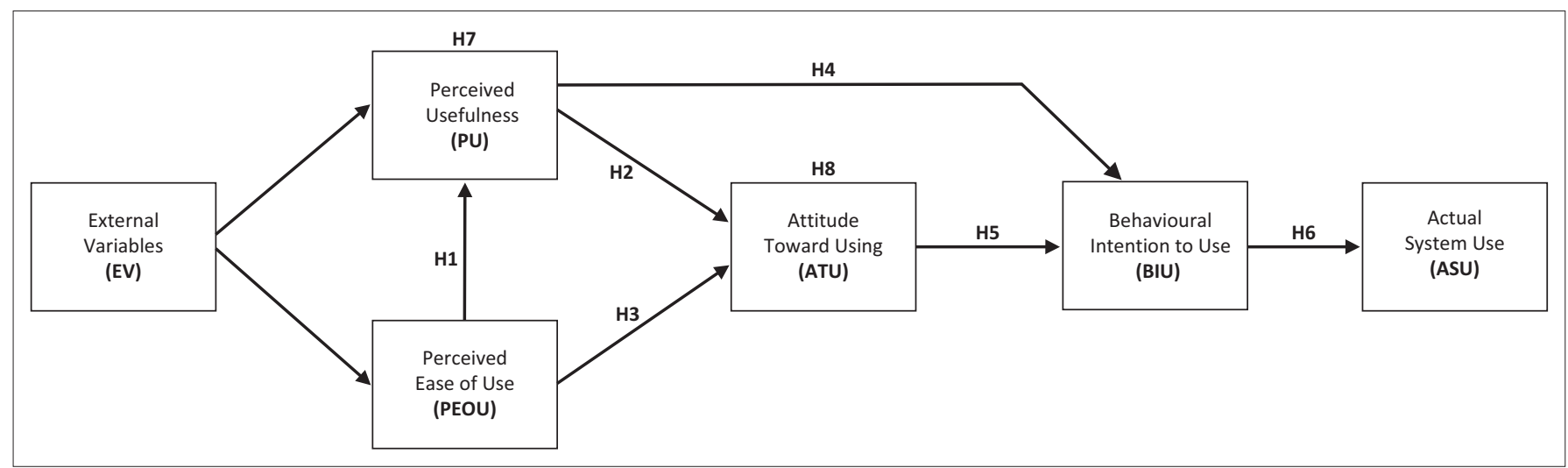

FIGURE 2: Internal relations between technology acceptance constructs.

\section{Hypothesis 6}

Behavioural intention to use an ERP system relates positively to actual system use during the user acceptance process of an ERP system.

To measure the indirect effects on both intention to use and actual system use, a further two hypotheses were formulated.

\section{Hypothesis 7}

Perceived ease of use affects behavioural intention to use an ERP system indirectly via attitudes towards use during the user acceptance process of an ERP system.

\section{Hypothesis 8}

Perceived usefulness affects actual system use indirectly via a behavioural intention to use during the user acceptance process of an ERP system.

\section{Method}

\section{Research design}

A cross-sectional survey design with questionnaires as the method of data collection was used to obtain information from the target population. According to Yang and Land (2008), this design is best suited for addressing the descriptive and predictive functions associated with correlational design in which relations between variables are examined.

\section{Participants}

The entire ERP user population of 720 employees within a steel manufacturing organisation in Gauteng was targeted for this research, but a response rate of only 33.5\% (241 participants) was obtained. The characteristics of the study population are detailed in Table 2. The majority of participants were white $(75.5 \%)$, male $(64.7 \%)$, between the ages of 29 and 55 years and holding a diploma or degree $(43.6 \%)$. These participants were mainly non-managerial employees $(66.8 \%)$ from the administration and services $(38.6 \%)$ and engineering (28.6\%) domains and with between five and ten years ERP experience (42.0).
TABLE 2: Characteristics of participants $(N=241)$.

\begin{tabular}{|c|c|c|c|}
\hline Item & Category & $f$ & $\%$ \\
\hline \multirow[t]{2}{*}{ Gender } & Male & 156 & 64.7 \\
\hline & Female & 85 & 35.3 \\
\hline \multirow[t]{6}{*}{ Age } & Below 22 & 2 & 0.8 \\
\hline & $23-28$ & 24 & 10.0 \\
\hline & 29-39 & 73 & 30.3 \\
\hline & $40-45$ & 45 & 18.6 \\
\hline & $46-55$ & 73 & 30.3 \\
\hline & over 55 & 24 & 10.0 \\
\hline \multirow[t]{4}{*}{ Education } & Below Grade 12 & 11 & 4.6 \\
\hline & Grade 12 & 89 & 36.9 \\
\hline & Diploma/degree & 105 & 43.6 \\
\hline & Post diploma/degree & 36 & 14.9 \\
\hline \multirow[t]{5}{*}{ Domain } & Manufacturing & 15 & 6.2 \\
\hline & Engineering & 69 & 28.6 \\
\hline & Financial & 38 & 15.8 \\
\hline & Information Technology & 26 & 10.8 \\
\hline & Administration/Services & 93 & 38.6 \\
\hline \multirow[t]{3}{*}{ Status } & Senior Management & 12 & 5.0 \\
\hline & Middle Management & 68 & 28.2 \\
\hline & Non-managerial & 161 & 66.8 \\
\hline \multirow[t]{5}{*}{ Enterprise Resource Planning years } & Less than 1 & 16 & 6.6 \\
\hline & $1-2$ & 16 & 6.6 \\
\hline & $2-5$ & 53 & 22.0 \\
\hline & $5-10$ & 101 & 42.0 \\
\hline & More than 10 & 55 & 22.8 \\
\hline
\end{tabular}

$f$, frequency

\section{Measuring instrument}

The Technology Acceptance Model Questionnaire (TAMQ) with 23 items was used for gathering data regarding the various constructs depicted in the core of the technology acceptance model, namely perceived usefulness, perceived ease of use, behavioural intention to use and attitude towards using and actual system use; the questionnaire was compiled by Malhotra and Galletta (1999). This scale was adapted from prior studies, many of which had already established reliability and validity. The Cronbach's alpha reliability scores for the core technology acceptance model constructs were found to range from 0.68 to 0.97 for perceived ease of use and from 0.71 to 0.96 for perceived usefulness (AmoakoGyampah \& Salam, 2004; Chau \& Hu, 2002; Guritno \& Siringoringo, 2013; Jamaluddin, 2013; Malhotra \& Galletta, 1999; Surendran, 2012; Taylor \& Todd, 1995; Venkatesh 
et al., 2003), from 0.69 to 0.92 for attitude towards using (Amoako-Gyampah \& Salam, 2004; Chau \& Hu, 2002; Taylor \& Todd, 1995; Venkatesh et al., 2003) and from 0.62 to 0.96 for behavioural intention to use (Amoako-Gyampah \& Salam, 2004; Chau \& Hu, 2002; Venkatesh et al., 2003).

Malhotra and Galletta (1999) established convergent validity and discriminant validity of all pre-existing technology acceptance model measures. Factor analysis provided evidence of distinct loadings of various factors and convergent and discriminant validity based on inter-item correlations. All constructs used in the technology acceptance model met the criteria of validity and reliability.

\section{Data analysis}

The data was statistically analysed by means of the SPSS, version 22, and the AMOS software programs. Descriptive statistics (e.g. means and standard deviations) were used to analyse the data. Pearson correlation coefficients were computed to determine the relations between variables. A cut-off point of 0.05 was set for the statistical significance $(p)$ of the results. Effect sizes (Cohen, 1988) were used to decide on the practical significance of the findings. A cut-off point of 0.30 (medium effect; Cohen, 1988) was set for the practical significance of correlation coefficients.

Structural equation modelling was used to assess the factorial validity of the measuring instruments' perceived usefulness, perceived ease of use, attitude towards using, behavioural intention to use and actual system use. Amongst the fit indices produced by the AMOS program is the Chi-square statistic $\left(\chi^{2}\right)$, which is the test of absolute fit of the model. However, the $\chi^{2}$ value is sensitive to sample size. Therefore, additional best-fit indices, such as the root means square error of approximation (RMSEA), standardised root mean residual (SRMR), degrees of freedom $(d f)$, Tucker-Lewis index (TLI), comparative fit index (CFI), Akaike information criterion (AIC), Bayes information criterion (BIC) and composite reliability (Raykov, 2009), were computed for each scale. Composite reliability $(\rho)$ is superior to Cronbach's alpha coefficients when latent variable modelling is used.

\section{Procedure}

This study was conducted at a South African steel manufacturer as part of their SAP ERP Consolidation Project, with the intent to determine user acceptance of the new consolidated system. The research sample was drawn from the SAP ERP users group, consisting of system users and technical specialists, over a 16-month period from September 2010 to December 2011. The battery of questionnaires was placed on the organisation's information portal by their systems administrator, so that participants could complete and submit it electronically online. Prior to placing the questions online, some hard copies of questionnaires were distributed and collected by the SAP basis technical department. The system's administrator extracted the completed questionnaire data from the information portal database and made them available to the researchers all data together with the hard copies. This data were verified and collated into a single database for statistical analysis.

\section{Ethical aspects}

The manager of the SAP Centre of Excellence (CoE) in the information management section at a South African steel manufacturer was approached and asked for permission to conduct this study. Permission in the form of a letter of consent was obtained with the precondition that all research findings will be made available to the SAP CoE manager. The Ethics Committee of the North-West University (NWU) approved the study. Participants were informed in the preamble to the questionnaire that: (1) data are captured by the researchers and not their organisation, (2) data will solely be used for academic research purposes and not for any job performance or merit objectives, (3) participation is voluntary and (4) participants will remain anonymous.

\section{Results \\ Testing the measurement model}

By way of confirmatory factor analysis (CFA), alternative measurement models were tested to assess whether the items loaded significantly onto the scales to which they were related. Using structural equation modelling (SEM) methods, as implemented by AMOS, six measurement models were tested. Model 1 was the technology acceptance model as proposed and validated by Davis (as cited in Koh et al., 2010) and Malhotra and Galletta (1999) and consisted of five latent variables, namely (1) perceived ease of use (measured by six observed variables), (2) perceived usefulness (measured by six observed variables), (3) attitude towards using (measured by four observed variables), (4) behavioural intention to use (measured by four observed variables) and (5) actual system use (measured by three observed variables). All the latent variables in model 1 were allowed to correlate.

Models 2-6 followed the same template: model 2 was specified with perceived ease of use and perceived usefulness merged into a general-perception latent variable; model 3 was specified with perceived usefulness and attitude towards using merged into a useful-attitude latent variable; model 4 was specified with perceived ease of use and attitude towards using merged into an ease-attitude latent variable; model 5 was specified with perceived usefulness, perceived ease of use and attitude towards using merged into a perceptualattitude latent variable; model 6 was specified with attitude towards using and behavioural intention to use merged into a motivation-attitude latent variable. Table 3 presents fit statistics for the test of the various models.

A $\chi^{2}$ value of $617.99(d f=220)$ was obtained for the hypothesised measurement model 1. The fit statistics on two fit indices were acceptable $(\mathrm{CFI}=0.91$; SRMR $=0.05)$. The fit statistics on the remaining two indices were near acceptable (TLI = 0.89; RMSEA = 0.09). Two additional fit statistics, namely the AIC and BIC, were used to compare alternative measurement 
TABLE 3: Fit statistics of competing measurement models.

\begin{tabular}{|c|c|c|c|c|c|c|c|c|}
\hline Model & $\chi^{2}$ & RMSEA & SRMR & $d f$ & TLI & CFI & AIC & BIC \\
\hline Model 1 & 617.99 & 0.09 & 0.05 & 220 & 0.89 & 0.91 & 729.98 & 925.13 \\
\hline Model 2 & 1436.34 & 0.15 & 0.11 & 224 & 0.68 & 0.72 & 1540.34 & 1721.55 \\
\hline Model 3 & 834.49 & 0.11 & 0.07 & 224 & 0.84 & 0.86 & 938.49 & 1119.69 \\
\hline Model 4 & 956.38 & 0.12 & 0.12 & 224 & 0.81 & 0.83 & 1060.382 & 1241.59 \\
\hline Model 5 & 1642.15 & 0.16 & 0.12 & 227 & 0.63 & 0.67 & 1740.15 & 1910.90 \\
\hline Model 6 & 819.29 & 0.11 & 0.07 & 224 & 0.84 & 0.86 & 923.29 & 1104.50 \\
\hline Model 7 & 549.81 & 0.08 & 0.05 & 219 & 0.91 & 0.92 & 663.81 & 862.450 \\
\hline
\end{tabular}

AIC, Akaike information criterion; BIC, Bayes information criterion; CFI, Comparative fit index; $d f$, degrees of freedom; RMSEA, root mean square error of approximation; SRMR, standardised root mean square residual; TLI, Tucker-Lewis index.

models. The AIC, which is a comparative measure of fit, is meaningful when different models are estimated. The lowest AIC is the best-fitting model. The BIC provides an indication of model parsimony. On these additional fit statistics model 1 rendered an AIC of 729.98 and a BIC of 925.13.1. Comparison of the fit indices indicates that model 1 fitted the data best.

Analysis continued in an exploratory manner to improve the fit of the selected model. The modification index (MI = 60.34) for item 14 ('I intend to use SAP for capturing ALL my work-related reports') and item 15 ('I intend to use SAP to generate all my work-related reports'), related to behavioural intention to use (BIU), indicated that the model fit could be improved by correlating the errors of these items. The fit statistics for the revised model (model 7) showed that the model fit improved significantly when the errors of the items were allowed to correlate. A $\chi^{2}$ value of $549.81(d f=219)$ was obtained for the hypothesised measurement model. The fit statistics on the six fit indices were acceptable (TLI $=0.91$; $\mathrm{CFI}=0.92 ; \mathrm{RMSEA}=0.08 ; \mathrm{SRMR}=0.05 ; \mathrm{AIC}=663.81$; $\mathrm{BIC}=862.45)$.

\section{Testing the structural model}

Table 4 shows the descriptive statistics, reliability coefficients and inter-item correlation coefficients of the technology acceptance model measuring instruments.

Scores on three of the dimensions, perceived ease of use, attitude towards using and behavioural intention to use, seem to be leptokurtic by peaking high with a kurtosis greater than 1 , confirming their frequency distributions to be concentrated around the centre. The remaining two, perceived usefulness and actual system use, seem to be platykurtic by peaking low with a kurtosis of less than 1, with their frequencies distribution concentrated widely around the distribution tail ends. All five dimensions are negatively skewed, which is indicative of most values being distributed to the right of the mean. A multivariate kurtosis score for the data of 280.55 with a critical ratio score of 64.22 was reported by AMOS, which is indicative of non-normality.

Composite reliability obtained using the method as proposed by Raykov (2009) rendered reliability coefficients ranging from 0.96 to 0.99 for the scales used in this study. This score surpassed the 0.70 cut-off point Nunnally and Bernstein (1994) propose and is therefore acceptable.
The correlation coefficients between perceived ease of use, perceived usefulness, attitude towards using, behavioural intention to use and actual system use (ASU) for employees working in a SAP ERP environment are reported in Table 5.

All correlation coefficients obtained were significant. Practically significant positive correlations of medium effect were obtained between perceived ease of use and perceived usefulness $(r=0.48)$ as well as between perceived ease of use and attitude towards using $(r=0.49)$, demonstrating higher user perceived usefulness and higher attitude towards using as a result of an increase in user perceived ease of use. Practically significant positive correlations of large effect were obtained between perceived usefulness and attitude towards using $(r=0.75)$ as well as between perceived usefulness and behavioural intention to use $(r=0.55)$, confirming that higher levels of perceived usefulness are associated with higher levels of end-user attitude towards using as well as end-user behavioural intention to use the SAP ERP system. Practically significantly positive correlations of medium effect were obtained between attitude towards using and behavioural intention to use $(r=0.48)$ as well as between behavioural intention to use and actual system use $(r=0.37)$, demonstrating that a higher attitude towards using positively enhances behavioural intention to use, which in turn leads to higher actual system use.

The structural model (model 8) was tested based on the measurement model (model 7). Model 8, which emerged as an over-identified structural model, having 276 unique covariance terms and 53 parameters, was tested rendering the following fit results: $\chi^{2}$ of $562.53(d f=223 ; p=0.00)$, RMSEA of 0.08 , SRMR of 0.06, TLI of 0.91 , CFI of 0.92 , AIC of 668.53 and BIC of 853.22. Figure 3 shows the standardised path coefficients estimated by AMOS.

Given the cross-sectional nature of the data, two competing models, models $8 \mathrm{a}$ and $8 \mathrm{~b}$, were also tested to determine possible redundancies amongst path coefficients. In model $8 \mathrm{a}$, the relation between perceived ease of use and perceived usefulness was annulled by constraining the path coefficient to zero. Results indicated a poor fit to the data $\left(\chi^{2}(224 ; N=\right.$ $241)=625.56 ; p<0.001 ; \mathrm{TLI}=0.89 ; \mathrm{CFI}=0.91$, RMSEA = 0.09, $\mathrm{SRMR}=0.19, \mathrm{AIC}=729.56 ; \mathrm{BIC}=910.77)$. A path coefficient in the remaining competing model $8 \mathrm{~b}$ was also constrained to zero: between perceived usefulness and attitude towards using. Model 8b rendered the following fit statistics: $\chi^{2}(224 ; N=241)$ 
TABLE 4: Descriptive statistics, reliability coefficients and correlation means coefficients and inter-item correlation coefficients of the TAM measuring instruments $(N=241)$.

\begin{tabular}{|c|c|c|c|c|c|c|}
\hline Measure & M & SD & Skewness & Kurtosis & Inter-item $\mathbf{r}$ & $\rho$ \\
\hline Perceived ease of use & 31.07 & 6.89 & -0.93 & 1.25 & 0.41 & 0.99 \\
\hline Perceived usefulness & 31.77 & 6.92 & -0.73 & 0.92 & 0.57 & 0.99 \\
\hline Attitude towards using & 21.05 & 4.74 & -0.86 & 1.13 & 0.56 & 0.96 \\
\hline Behavioural intention to use & 23.74 & 4.22 & -1.23 & 1.75 & 0.44 & 0.96 \\
\hline Actual system use & 16.91 & 4.66 & -1.07 & 0.19 & 0.43 & 0.98 \\
\hline
\end{tabular}

$\mathrm{M}$, mean; SD, standard deviation

TABLE 5: Correlation coefficients between perceived ease of use, perceived usefulness, attitude towards using, behavioural intention to use and actual system use $(N=241)$.

\begin{tabular}{|c|c|c|c|c|}
\hline Variable & 1 & 2 & 3 & 4 \\
\hline 1. Perceived ease of use & - & - & - & - \\
\hline 2. Perceived usefulness & $0.48 * \dagger$ & - & - & - \\
\hline 3. Attitude towards using & $0.49 * \dagger$ & $0.75 *+\dagger$ & - & - \\
\hline 4. Behavioural intention to use & $0.35 * \dagger$ & $0.55 *+\dagger$ & $0.48 * \dagger$ & - \\
\hline 5. Actual system use & $0.32 * \dagger$ & $0.49 * \dagger$ & $0.52 *+\dagger$ & $0.37 * \dagger$ \\
\hline
\end{tabular}

*, Statistically significant $(p<0.01)$

$\dagger$, Correlation is practically significant $(r \geq 0.30$; medium effect)

$\dagger$, Correlation is practically significant $(r \geq 0.50$; large effect)

TABLE 6: Fit statistics of competing structural models.

\begin{tabular}{|c|c|c|c|c|c|c|c|c|}
\hline Model & $\chi^{2}$ & RMSEA & SRMR & $d f$ & TLI & CFI & AIC & BIC \\
\hline Model 8 & 562.53 & 0.08 & 0.06 & 223 & 0.91 & 0.92 & 668.53 & 853.22 \\
\hline Model 8a & 625.56 & 0.09 & 0.19 & 224 & 0.89 & 0.91 & 729.56 & 910.77 \\
\hline Model 8b & 608.64 & 0.09 & 0.11 & 224 & 0.90 & 0.91 & 712.64 & 893.85 \\
\hline
\end{tabular}

AIC, Akaike information criterion; BIC, Bayes information criterion; CFI, comparative fit index; $d f$, degrees of freedom; RMSEA, root mean square error of approximation; SRMR, standardised root mean square residual; TLI, Tucker-Lewis index.

of 608.64, TLI of 0.90, CFI of 0.91, RMSEA of 0.09, SRMR of 0.11 , AIC of 712.64 and BIC of 893.85 . Table 6 presents fit statistics for the various structural models.

Upon inspection of Table 6, model 8 emerged as the best fitting and most parsimonious structural model revealing the lowest $\chi^{2}$ (562.53), $d f(223)$ and AIC (668.53) values. Furthermore, all other fit statistics, RMSEA (0.08), SRMR (0.06), TLI (0.91) and CFI (0.92, were within acceptable bounds. The following changes in chi-square $\left(\Delta \chi^{2}\right)$ were found: model 8 and model 8 a had a $\Delta \chi^{2}$ value of $63.03(\Delta d f=1$; $p<0.01)$, whilst model 8 and model $8 \mathrm{~b}$ showed a $\Delta \chi^{2}$ value of $46.11(\Delta d f=1, p<0.01)$. The AIC and BIC values of model 8 were also substantially lower than the values for model $8 \mathrm{a}$ and model $8 \mathrm{~b}$. Therefore, model 8 will be discussed with reference to the hypotheses of this study by referring to the relevant standardised regression weights as per Figure 3.

\section{Hypothesis 1}

Inspection of the standardised regression weights revealed a positive relation $(\beta=0.51$ ) between perceived ease of use and perceived usefulness towards using SAP ERP. The MLestimated equation accounted for a large proportion of the variance in perceived usefulness $\left(R^{2}=0.26\right)$. Hypothesis 1 is accepted.

\section{Hypothesis 2}

The standardised regression weights obtained for the relation between perceived usefulness and attitude towards using SAP ERP was also positive $(\beta=0.51)$. The MLestimated equation accounted for a large proportion of the variance in attitude towards using $\left(R^{2}=0.35\right)$. Hypothesis 2 is accepted.

\section{Hypothesis 3}

The standardised regression weights for the relation between perceived ease of use and attitude towards using SAP ERP was positive $(\beta=0.13)$, but the effect size was small.

\section{Hypothesis 4 and hypothesis 5}

The standardised regression weight obtained for the relation between perceived usefulness and behavioural intention to use SAP ERP was positive $(\beta=0.81)$. The standardised regression weights for the relation between attitude towards using and behavioural intention to use SAP ERP was positive $(\beta=0.10)$. Although the ML-estimated equation accounted for a large proportion of the variance in behavioural intention to use $\left(R^{2}=0.76\right)$, attitude towards using had a small effect, whilst perceived usefulness had a large effect. Hypothesis 4 and hypothesis 5 are accepted.

\section{Hypothesis 6}

The standardised regression weight obtained for the relation between behavioural intention to use SAP ERP and actual system use was positive $(\beta=0.62)$. The ML-estimated equation accounted for a large proportion of the variance in actual system use $\left(R^{2}=0.38\right)$. Hypothesis 6 is accepted. 


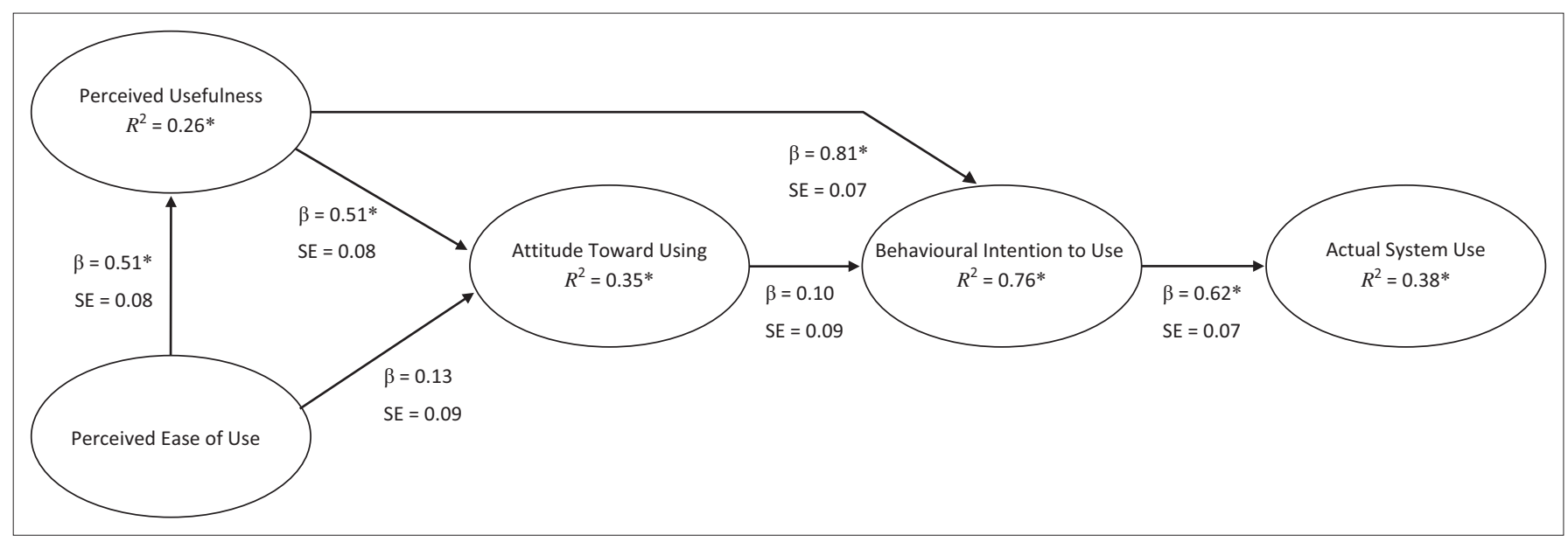

FIGURE 3: Structural model of technology acceptance.

TABLE 7: Indirect effects of perceived ease of use and perceived usefulness.

\begin{tabular}{|c|c|c|c|}
\hline Variable & Estimate & SE & $\begin{array}{l}95 \% \text { bias-corrected } \\
\text { confidence interval }\end{array}$ \\
\hline PEOU to BIU & 0.45 & 0.07 & {$[0.31,0.60]$} \\
\hline PEOU to ATU & 0.26 & 0.06 & {$[0.16,0.41]$} \\
\hline PU to ASU & 0.53 & 0.06 & {$[0.41,0.65]$} \\
\hline PU to BIU & 0.50 & 0.05 & {$[-0.03,0.16]$} \\
\hline
\end{tabular}

$\mathrm{SE}$, standard error; ASU, actual system use; ATU, attitude towards using; BIU, behavioural intention to use; PEOU, perceived ease of use; PU, perceived usefulness.

\section{Hypothesis 7}

To determine whether perceived ease of use indirectly affected behavioural intention to use via attitude towards using, the procedure as explained by Hayes (2009) was used. Two-sided bias-corrected, 95\% confidence intervals (CIs) were constructed using bootstrapping so as to evaluate indirect effects and were proved not to include zero. The obtained lower CIs (LCIs) and upper CIs (UCIs) are reported in Table 7. Perceived ease of use affected behavioural intention to use SAP ERP indirectly via attitude towards using. Hypothesis 7 is accepted.

\section{Hypothesis 8}

Again two-sided bias-corrected 95\% confidence intervals were, as suggested by Hayes (2009), constructed using bootstrapping in order to assess indirect effects. The relevant LCIs and UCIs are reported in Table 7. The 95\% CIs for the indirect effect of perceived usefulness on behavioural intention to use (via attitude towards use) did not include zero. The $95 \%$ CIs of perceived usefulness on actual system use (via behavioural intention to use) did not include zero. Therefore perceived usefulness affected actual information system use indirectly via the behavioural intention to use it. Hypothesis 8 is accepted.

\section{Discussion}

The aim of this study was to test the technology acceptance model within a South African SAP ERP user environment. Results acquired through structural equation modelling confirmed that positive inter-construct relation exists between all technology acceptance model constructs. Actual system use, which is the measurement for technology acceptance, was directly affected by behavioural intention to use and indirectly by perceived usefulness. In turn, behavioural intention to use was directly affected by perceived usefulness and attitude towards using and indirectly affected by perceived ease of use. Attitude towards using was directly affected by perceived ease of use and perceived usefulness. Perceived usefulness was directly affected by perceived ease of use.

Structural equation modelling rendered a best fit model that confirmed a positive statistically significant path leading from perceived ease of use through perceived usefulness and behavioural intention to use to actual system use. This path commences with a significant relation between perceived ease of use and perceived usefulness (explaining 26\% of the variance). This finding is consistent with findings reported by Amoako-Gyampah and Salam (2004), Averweg (2008), Chau and Hu (2002), Jamaluddin (2013), Koh et al. (2010) and Venkatesh and Davis (2000).

As expected, perceived usefulness of the information system was strongly associated with the behavioural intention to use it $(76 \%$ of the variance explained). This finding is consistent with that reported by Davis (1989) (as cited in Koh et al., 2010), Malhotra and Galletta (1999) and Taylor and Todd (1995), but inconsistent with findings of Gumussoy et al. (2007), who reported it to be of medium practical effect. This discrepancy may be attributed to the fact that the Gumussoy et al. study focused on potential ERP users and not existing users as in this study. Potential users will obviously not have any experience with ERP. Therefore, they will not have a well-founded sense of usefulness. Amoako-Gyampah and Salam (2004) reported this relation to be non-significant. The Amoako-Gyampah and Salam study was done during an ERP implementation amidst prospective users with no or little system experience. Their study focused primarily on three external projectrelated variables, namely (1) project communication related to the ERP system, (2) shared belief in the benefits of the ERP system and (3) training on the ERP system. Obviously these participants had no sense of usefulness and were unable to formulate an intention towards using the system. 
The behavioural intention to use the system was strongly related to actual system use (38\% of the variance shared). This finding is consistent with that reported by Davis (as cited in Koh et al., 2010) and Malhotra and Galletta (1999), but inconsistent with Shih and Huang (2009), who reported it as being of medium effect. Shih and Huang conducted their research prior to an ERP implementation incorporating additional behavioural constructs such as: (1) top management support, (2) computer self-efficacy and (3) computer anxiety. This finding of Shih and Huang could possibly be attributed to a lack of hands-on experience; thus, potential users were unable to formulate a behavioural intention to use the system.

The significance of identifying this relation path to system use is that organisations can focus on appropriate interventions prior to system upgrades and modifications, in order to secure the optimal use of their ERP system amongst existing users. Therefore, during such ERP renewal projects, change management endeavours could focus on influencing the user's perceptions regarding the ease of use together with usefulness of the adapted system. Subsequently, through emphasising the benefits of these adaptations, their intentions to use the modified system can positively be influenced.

The results of this study confirm the important role of the perceived ease of use and perceived usefulness of technology in the acceptance thereof. Perceived ease of use strongly affected perceived usefulness, whilst perceived usefulness strongly affected attitudes towards system use as well as the behavioural intention to use it. The findings confirmed that perceived ease of use indirectly affected individuals' attitudes towards use (via perceived usefulness). Moreover, perceived ease of use also indirectly affected the behavioural intention to use the system (via perceived usefulness). Perceived usefulness of the information system seems to play a pivotal role in the model: it affected attitudes towards system use, but also the behavioural intention to use the system.

Attitude towards system use did not play an important role in affecting behavioural intentions to use it or the actual use thereof in this study. Although perceived usefulness of the information system strongly affected attitudes towards using it, the relation of attitudes to behavioural intention to use was insignificant. One reason for this finding could be a possible overlap between the constructs of perceived usefulness and attitudes towards use. However, an evaluation of the measurement models showed that these constructs could be modelled independently. This observation corresponds with the model of Gumussoy et al. (2007), but differs from that of Amoako-Gyampah and Salam (2004), who found the strength of the relation between attitude towards using and behavioural intention to use highly significant $(r=0.75)$. This inconsistency could be attributed to differences in user cultures in South Africa and the United States of America or the period of user exposure to ERP. The South African study was conducted amongst existing ERP users whereas Amoako-Gyampah and Salam focused on potential ERP users prior to an ERP implementation.

This study had several limitations. Firstly, the sample size has a limitation, specifically the distribution of cultural groups, age generations and gender. This limitation could be ratified by a stratified random sampling approach of larger samples and by securing adequate representation of participants in each of these categories. Another limitation was that the measurement of this technology acceptance model variables was based upon self-reports. According to Halbesleben and Buckley (2004), the exclusive use of selfreport measures increases the likelihood that at least part of the shared variance between measures can be attributed to method variance. Thirdly, the study population was very homogeneous, since from a sample of 241 respondents, $64.7 \%$ were male and $75.5 \%$ were white. South Africa's multicultural society demands studying the constructs of technology acceptance from different cultural group perspectives, by ensuring construct equivalence in the absence of item bias for these groups. Stratified random sampling might amend this inadequacy.

\section{Recommendations}

This study validated the technology acceptance model within a South African context and it paved the way for future researchers to reconstruct an improved technology acceptance model at the hand of South African tailored measures. Practically, this study implies the possible determining of SAP ERP end-user acceptance of new functional additions due to system upgrades and functional add-ons. Furthermore, corporate leadership could select and recruit super users by means of the model and measures used in this study and, in so doing, work towards higher levels of returns on their information technology investment.

A typical intervention rationale could be, firstly, to build user confidence by proving the ease of use of the renewed system. Secondly, it is necessary to reiterate the usefulness and future added value to the user's job and career by employing the system in question. Thirdly, through relevant education, training and guidance initiatives, users could be motivated to use the system. Lastly, it is necessary to ensure on-going user support.

Future studies should include larger sample sizes obtained through stratified random sampling to secure adequate representation in all sample categories, in order to prevent a homogenous sample model. Future studies could also follow a longitudinal design in which causal inferences can be made prior to SAP ERP system upgrades or functional enhancements. This will enable an understanding of the motivational impact such changes have on end users. Lastly, future research should consider including the generational theory solely to determine the aptitude and consequent acceptance of new IT technologies. This will enable corporate leadership to successfully interact with each generation 
during system changes and developments, to ensure higher levels of acceptance.

Future studies within South Africa should be conducted using other relevant external variables as suggested by previous researchers, namely project communication (Somers \& Nelson, 2004), senior management support (AlMashari et al., 2003), ethnic differences (Yusuf et al., 2004), effective systems integration (Al-Mashari et al., 2003) and system training (Amoako-Gyampah \& Salam, 2004). Considering ERP renewal projects, it is recommended that future studies focus on the practical composition of change management user interventions to secure acceptance of the renewed system by way of utilising the findings of this study.

\section{Acknowledgements Competing interests}

The authors declare that they have no financial or personal relationships that may have inappropriately influenced them in writing this article.

\section{Authors' contributions}

E.E. (North-West University), S.R. (North-West University) and C.v.E. (North-West University) contributed equally to the writing of this article.

\section{References}

Abugabah, A., \& Sanzogni, L. (2010). Enterprise resource planning (ERP) system in higher education: A literature review and implications. International Journal of Human and Social Sciences, 5, 395-399.

Adam, R., Kotzé, P., \& Van der Merwe. A. (2011). Acceptance of enterprise resource planning. Systems by small manufacturing enterprises. Proceedings of the 13th International Conference on Enterprise Information Systems, Beijing, China.

Ajzen, I., \& Fishbein, M. (1975). Understanding attitudes and predicting social behavior. Englewood Cliffs, NJ: Prentice-Hall.

Ajzen, I., \& Madden, T.J. (1986). Prediction of goal-directed behavior: Attitudes, intentions, and perceived behavioral control. Journal of Experimental Socia Psychology, 22, 453-474. http://dx.doi.org/10.1016/0022-1031(86)90045-4

Al-Mashari, M., Al-Mudimigh, A., \& Zairi, M. (2003). Enterprise resource planning: A taxonomy of critical factors. European Journal of Operational Research, 146, 352-364. http://dx.doi.org/10.1016/S0377-2217(02)00554-4

Amoako-Gyampah, K., \& Salam, A.F. (2004). An extension of the technology acceptance model in an ERP implementation environment. Information \& Management, 41, 731-745. http://dx.doi.org/10.1016/j.im.2003.08.010

AMOS (21.0) [Computer software]. (2012). Chicago, IL: SPSS Inc.

Averweg, U.R. (2008). Information technology acceptance in South Africa: An investigation of perceived usefulness, perceived ease of use, and actual system use constructs. The African Journal of Information Systems, 1, 44-66.

Beyleveld, A., \& Schurink, W. (2005). The social construction of systems applications products (SAP) R/ 3 by employees of a South African chemical industries company. SA Journal of Human Resource Management, 3, 22-33. http://dx.doi.org/10.4102/ sajhrm.v3i1.59

Brown, I.T.J. (2002). Individual and technical factors affecting perceived ease of use of web-based learning technology in developing countries. The Electronic Journal on Information Systems in Developing Countries, 9, 1-15.

Cable, D.A.J., \& O'Driscoll, M.P. (2010). The practice of industrial/organisational psychology in New Zealand. New Zealand Journal of Psychology, 39(3), 12-18.

Castaneda, D., \& Toulson, P. (2013). The value of human resources measurement in intellectual capital and knowledge sharing. The Electronic Journal of Knowledge Management, 11, 226-234.

Chau, P.Y.K., \& Hu, P.J.H. (2002). Investigating healthcare professionals' decisions to accept telemedicine technology: An empirical test of competing theories. Information \& Management, 39, 297-311. http://dx.doi.org/10.1016/S0378 7206(01)00098-2

Cohen, J. (1988). Statistical power analysis for the behavioural sciences. (rev. edn.). Orlando, FL: Academic Press.
Davis, F.D. (1986). A technology acceptance model for empirically testing new enduser information systems: Theory and results. Unpublished doctoral thesis, MIT Sloan School of Management, Cambridge, MA.

Davis, F.D. (1989). Perceived usefulness, perceived ease of use, and user acceptance of information technology. MIS Quarterly, 13(3), 318-339. http://dx.doi. org $/ 10.2307 / 249008$

Davis, F.D., Bagozzi, R.P., \& Warshaw, P.R. (1989). User acceptance of computer technology: A comparison of two theoretical models. Management Science, 35, 982-1003. http://dx.doi.org/10.1287/mnsc.35.8.982

Esteves-Sousa, J., \& Pastor-Collado, J. (2000). Towards the unification of critical success factors for ERP-implementations. Paper presented at the 10th Annual Business Information Technology Conference (BIT), Manchester, United Kingdom.

Etsebeth, E. (2012). Trialability, perceived risk and complexity of understanding as determinants of cloud computing services adoption. Unpublished MBA dissertation, University of Pretoria, Pretoria, South Africa.

Gefen, D., \& Straub, D. (2000). The relative importance of perceived ease of use in IS adoption: A study of e-commerce adoption. Journal of the Association for Information Systems, 8, 1-28.

Gumussoy, C.A., Calisir F., \& Bayram, A. (2007). Understanding the behavioral intention to use ERP systems: An extended technology acceptance model. Proceedings of the International Conference on Industrial Engineering and Engineering Management (IEEE), Singapore. http://dx.doi.org/10.1109/IEEM.2007.4419547

Guritno, R.S., \& Siringoringo, H. (2013). Perceived usefulness, ease of use, and attitude towards online shopping usefulness towards online airlines ticket purchase. ProcediaSocial and Behavioral Sciences, 81, 212-216. http://dx.doi.org/10.1016/j. sbspro.2013.06.415

Halbesleben, J.R.B., \& Buckley, M.R. (2004). Burnout in organizational life. Journal of Management, 30, 859-879. http://dx.doi.org/10.1016/j.jm.2004.06.004

Hayes, A.F. (2009). Beyond Baron and Kenny: Statistical mediation analysis in the new millennium, Communication Monographs, 76, 408-420. http://dx.doi. org/10.1080/03637750903310360

Hong, K.K., \& Kim, Y.G. (2002). The critical success factors for ERP implementation: An organizational fit perspective. Information and Management, 40, 25-40. http:// dx.doi.org/10.1016/S0378-7206(01)00134-3

Hong, W., Thong, J.Y.L., Wong, W., \& Tam, K. (2002). Determinants of user acceptance of digital libraries: An empirical examination of individual differences and system characteristics. Journal of Management Information Systems, 18, 97-124.

Jamaluddin, N. (2013). Adoption of e-commerce practices among the Indian farmers: A survey of Trichy District in the State of Tamilnadu, India. Procedia Economics and Finance, 7, 140-149. http://dx.doi.org/10.1016/S2212-5671(13)00228-1

King, W.R., \& He, J. (2006). A meta-analysis of the technology acceptance model. Information \& Management, 43, 740-755. http://dx.doi.org/10.1016/j.im.2006. 05.003

Koh, C.E., Prybutok, V.R., Ryan, S.D., \& Wu, Y. (2010). A model for mandatory use of software technologies: An integrative approach by applying multiple levels of abstraction of informing science. Informing Science: The International Journal of an Emerging Transdiscipline, 13, 177-203.

Kumar, V., Maheshwari, B., \& Kumar, U. (2003). An investigation of critical management issues in ERP implementation: Empirical evidence from Canadian organizations. Technovation, 23, 793-807. http://dx.doi.org/10.1016/S0166-4972(02)00015-9

Lee, Y., Kozar, K.A., \& Larsen, K.R.T. (2003). The technology acceptance model: Past, present, and future. Communications of the Association for Information Systems, 12, 752-780.

Legris, P., Ingham, J., \& Collerette, P. (2003). Why do people use information technology? A critical review of the technology acceptance model. Information \& Management, 40, 191-204. http://dx.doi.org/10.1016/S0378-7206(01)00143-4

Leonard, L.N.K., Cronan, T.P., \& Kreie, J. (2004). What influences IT ethical behavior intentions, planned behavior, reasoned action, perceived importance, or individual characteristics? Information and Management, 42, 143-158. http:// dx.doi.org/10.1016/j.im.2003.12.008

Liang, H., Saraf, N., Hu, Q., \& Xue, Y. (2007). Assimilation of enterprise systems: The effect of institutional pressures and the mediating role of top management. MIS Quarterly, 31, 59-87.

Liao, S., Shao, Y.P., Wang, H., \& Chen, A. (1999). The adoption of virtual banking: An empirical study. International Journal of Information Management, 19, 63-74. $\mathrm{http} / / / \mathrm{dx}$.doi.org/10.1016/S0268-4012(98)00047-4

Malhotra, Y., \& Galletta, D.F. (1999). Extending the technology acceptance model to account for social influence: Theoretical bases and empirical validation. to account for social influence: Theoretical bases and empirical validation. http://dx.doi.org/10.1109/HICSS.1999.772658

Malhotra, Y \& Galletta, D.F. (2005). A multidimensional commitment model of volitional systems adoption and usage behavior Journal of Management Information Systems, 22, 117-151.

Meade, N., \& Islam, T. (2006). Modelling and forecasting the diffusion of innovation: A 25 -year review. International Journal of Forecasting, 22, 519-545. http://dx.doi. org/10.1016/j.ijforecast.2006.01.005

Moon, J.W., \& Kim, Y.G. (2001). Extending the TAM for a world-wide web context. Information and Management, 38, 217-230. http://dx.doi.org/10.1016/S03787206(00)00061-6

Nah, F.F.-H., \& Lau, J.L.-S. (2001). Critical factors for successful implementation of enterprise systems. Business Process Management Journal, 7, 285-296. http:// dx.doi.org/10.1108/14637150110392782 
Nunnally, J.C., \& Bernstein, I.H. (1994). Psychometric theory (3rd edn.). New York, NY: McGraw-Hill.

Raykov, T. (2009). Evaluation of scale reliability for unidimensional measures using latent variable modelling. Measurement and Evaluation in Counseling and Development, 42, 223-232. http://dx.doi.org/10.1177/0748175609344096

Recker, J., Rosemann, M., Green, P., \& Indulska, M. (2006). Extending the scope of representation theory: A review and a proposed research model. Proceedings of the Information Systems Foundations: Theory, Representation and Reality, 3rd ANU Information Systems Foundations Workshop, Canberra, Australia.

Rogers, E. (1995). Diffusion of innovations. New York, NY: Free Press.

Saade, R., \& Bahli, B. (2005). The impact of cognitive absorption on perceived usefulness and perceived ease of use in on-line learning: An extension of the technology acceptance model. Information Management, 42, 317-327. http:// dx.doi.org/10.1016/j.im.2003.12.013

Schultz, D., \& Schultz, S.E. (2014). Psychology and work today. Essex, United Kingdom: Pearson Education.

Seymour, L., Makanya, W., \& Berrangé, S. (2007). End-users' acceptance of enterprise resource planning systems: An investigation of antecedents. Proceedings of the 6th Annual ISOnEworld Conference (pp. 1-22), Las Vegas.

Shih, Y., \& Huang, S. (2009). The actual usage of ERP systems: An extended technology acceptance perspective. Journal of Research and Practice in Information Technology, 41, 263-276.

Soh, C., Kien, S., \& Tay-Yap, J. (2000). Cultural fits and misfits: Is ERP a universal solution? Communication of the ACM, 43, 47-51. http://dx.doi.org/10.1145/332051.332070

Somers, T.M., \& Nelson, K.G. (2004). A taxonomy of players and activities across the ERP project life cycle. Information and Management, 41, 257-278. http://dx.doi. org/10.1016/S0378-7206(03)00023-5

SPSS Statistics for Windows (Version 22.0) [Computer software]. (2013). Armonk, NY: IBM Corp.

Surendran, P. (2012). Technology acceptance model: A survey of literature. International Journal of Business and Social Research, 2, 175-178.

Taylor, S., \& Todd, P.A. (1995). Understanding information technology usage: A test of competing models. Institute for Operations Research and the Management Science, 6, 144-176. http://dx.doi.org/10.1287/isre.6.2.144
Tome, L, Johnston K.A., Meadows, A., \& Nyemba-Mudenda, M. (2014). Barriers to open source ERP adoption in South Africa. The African Journal of Information Systems, 6, 26-47.

Turner, D., \& Chung, S.H. (2005). Technological factors relevant to continuity on ERP for e-business platform: Integration, modularity, and flexibility. Journal of Internet Commerce, 4, 119-132. http://dx.doi.org/10.1300/J179v04n04_08

Umble, E.J., Haft, R.R., \& Umble, M.M. (2003). Enterprise resource planning: Implementation procedures and critical success factors. European Journal of Operational Research, 146, 241-257. http://dx.doi.org/10.1016/s0377 2217(02)00547-7

Venkatesh, V., \& Davis, F.D. (2000). A theoretical extension of the technology acceptance model: Four longitudinal field studies. Management Science, 46(2), 186-204. http://dx.doi.org/10.1287/mnsc.46.2.186.11926

Venkatesh, V., Morris, M.G., Davis, G.B., \& Davis, F.D. (2003). User acceptance of information technology: Toward a unified view. MIS Quarterly, 27, 425-478.

Wu, J., \& Wang, S. (2005). What drives mobile commerce? An empirical evaluation of the revised technology acceptance model. Information Management, 42, 719729. http://dx.doi.org/10.1016/j.im.2004.07.001

Wua, L.-C., Onga, C.-S., \& Hsub, Y.-W. (2008). Active ERP implementation management A real options perspective. Journal of Systems and Software, 81, 1039-1050. http://dx.doi.org/10.1016/j.jss.2007.10.004

Yang, Y., \& Land, K.C. (2008). Age - period - cohort analysis of repeated cross-section surveys: Fixed or random effects? Sociological Methods \& Research, 36, 297-326. http://dx.doi.org/10.1177/0049124106292360

Youngberg, E., Olsen, D., \& Hauser, K. (2009). Determinants of professionally autonomous end user acceptance in an enterprise resource planning system environment. International Journal of Information Management, 29, 138-144. http://dx.doi.org/10.1016/j.ijinfomgt.2008.06.001

Yu, P., Li, H., \& Gagnonc, M. (2009). Health IT acceptance factors in long-term care facilities: A cross-sectional survey. International Journal of Medical Informatics, 78, 219-229. http://dx.doi.org/10.1016/j.ijmedinf.2008.07.006

Yusuf, Y., Gunasekaran, A., \& Abthorpe, M.S. (2004). Enterprise information systems project implementation: A case study of ERP in Rolls-Royce. Internationa Journal of Production Economics, 87, 251-266. http://dx.doi.org/10.1016/j. ijpe.2003.10.004 